\title{
Issues related to waste sewage sludge drying under superheated steam
}

\author{
Ihsan Hamawand ${ }^{1,}$, Wilton Pereira da Silva ${ }^{2}$, Friederike Eberhard ${ }^{1}$, Diogenes L. Antille ${ }^{1}$ \\ ${ }^{1}$ University of Southern Queensland, National Centre for Engineering in Agriculture, Toowoomba,QLD, Australia \\ ${ }^{2}$ Federal University of Campina Grande, Paraíba, Brazil \\ "Corresponding author: e-mail: Ihsan.hamawand@usq.edu.au
}

\begin{abstract}
Sewage sludge was dried in a rotary drum dryer under superheated steam. Particle size and moisture content were shown to have significant influences on sticking and agglomeration of the materials. Pouring partially dried sludge (70-80\% moisture content, wet basis) directly into the screw feeder of the drum dryer resulted in a significant sticking to the surface of the drum and the final particle size of the product was greater than $100 \mathrm{~mm}$ in diameter. The moisture content of this product was slightly less than its initial value. To overcome this issue, the sludge was mixed with lignite at variety ratios and then chopped before being introduced to the feeding screw. It was found that mixing the sludge with lignite and then sieving the chopped materials through a four millimetre mesh sieve was the key to solve this issue. This technique significantly reduced both stickiness and agglomeration of the material. Also, this enabled for a significant reduction in moisture content of the final product.
\end{abstract}

Keywords: Sewage sludge, agglomeration, sticking, liquid bridge, rotary drum dryer, superheated steam.

\section{INTRODUCTION}

Sticking is often recognised as a challenging problem to deal with during drum drying 1 . Drums are usually made of cast iron, which has a relatively high surface energy $\left(\geq 70 \mathrm{mN} \mathrm{m}^{-1}\right)$. Surface energy is related to solid surface wettability which is responsible for building liquid bridges between two surfaces ${ }^{2}$. The stickiness of waste materials during drying is determined by adhesion and cohesion. The interfacial surface energy of the equipment and the material plays a critical role in controlling adhesion, whereas cohesion is influenced by interface diffusion and viscoelastic behaviour ${ }^{2}$. Some materials exhibit a strong tendency to adhere to contact surfaces, which are generally referred to as stickiness. In some circumstances, stickiness is desirable during material processing because it favours agglomeration, however, it can pose a problem in manufacturing operations leading to lower product yield, operational difficulties, equipment wear, and fire hazard. Therefore this problem has received considerable attention in the food as well as other industries ${ }^{2}$. The methods used to quantify stickiness are empirical, and there is no general consent as to what factors and forces are involved in stickiness. Many studies have attributed stickiness to either adhesive forces or to combined effects of adhesive and cohesive forces, viscosity, and liquid bridge ${ }^{3,4,5}$.

One way to manage sewage sludge is to dry it, which yields a solid that is low in humidity ${ }^{6}$. It is evident that for all proposed waste water sludge management options, drying constitutes an important step. It reduces the volume of sludge and consequently decreases the cost of handling, transport and storage of the final product ${ }^{7}$. Drying and thermal treatment of sewage sludge is becoming increasingly popular ${ }^{8}$. By taking into consideration the content of sludge heavy metals, the final product can partially or totally replace commercially available inorganic fertilizers in agricultural applications ${ }^{9}$ and/or in cement kiln ${ }^{10}$.

The process of drying involves the removal of water from a given material by means of heat and is usually conducted under controlled conditions ${ }^{11}$. For sludge, this process increases the storage life of the material and decreases transportation $\operatorname{costs}^{12}$. The reduction of moisture content in the material decreases water activity, which suppresses microbial growth during storage. There is a clear need to improve available technologies for drying of sludge in order to: a. reduce energy consumption, b. reduce the size of equipment, c. enhance quality control, e. reduce emissions, f. increase safety, and g. improve overall product quality including uniformity of drying, particle size and size distribution, and reduce physico-chemical and nutritional degradation ${ }^{13}$. The process of drying can be performed using two types of methods involving different media. These are for example hot gases such as hot air and hot solvent vapours such as water steam. The main advantage of hot air is that it is a relatively inexpensive drying medium whereas water steam has demonstrated advantages in drying explosive materials. Research has shown a number of advantages of steam drying compared to air drying. Proof of concepts for steam drying of paper and textiles have been accomplished $^{14}$. Soponronnarit et al. (2006) ${ }^{15,16}$ suggest that environmental pollution and odour can be significantly reduced by the use of steam because drying occurs in a closed chamber. Further studies demonstrated that the use of superheated steam as a drying medium for non-temperature sensitive products presents a number of benefits to consumers and industry ${ }^{17,18,19,20,21,22}$. For example, it enables energy savings in excess of $50 \%$ compared with hot air or flue gases ${ }^{17,23}$. Such reduction in energy consumption is due to higher heat transfer coefficients and increases in drying rates in both the constant and falling periods, which can be accomplished if the steam temperature is above the inversion temperature. Superheated steam drying means that there is an oxygen free environment during drying, so there are no oxidative or combustion reactions during the process, which eliminates fire or explosion hazards. This oxygen-free environment also results in improved product quality since opportunities for burning of the material are significantly reduced. In most circumstances, superheated steam drying is designed as a closed system. 
Consequently, toxic and highly volatile compounds are collected before they reach the environment and then removed, thus reducing air pollution. At the same time, dust generated during the drying process can be safely collected. Processing in superheated steam enables for concurrent blanching, pasteurisation, sterilisation, and deodorisation of food products during drying. Products also become partially cooked with potentially beneficial changes in textural properties. Some valuable volatile organic compounds generated from the drying material can be recovered and separated by a condenser. Examples of applications involving steam drying are drying of fuels and biofuels with relatively high moisture content prior to combustion including drying of cattle feed, sugar beet pulp, lumber, paper, paper pulp and sludge ${ }^{\mathbf{2 4}}$. There are other methods of drying sludge effectively such as fry-drying in oil, however this method will only be efficient when the sludge product is for fuel purposes ${ }^{25}$.

An important aspect relating to sticking and agglomeration is the initial condensation that takes place during the initial stages of the drying process ${ }^{\mathbf{2 6}}$. This phenomenon greatly influences the final quality of the material after drying and is responsible for fast heating even of the interior of the material. Although research into drying techniques using superheated steam on a range of materials has received considerable attention; there is still limited data available on the effectiveness of this method for drying of sludge and sludge-lignite mixtures. Therefore, the objectives of this study were to: (1) Determine the feasibility of drying of sludge and sludge-lignite mixtures with high initial moisture content using superheated stem in an industrial rotary drum dryer, and (2) Provide a set of recommendations to minimise sticking and agglomeration that commonly occur with the use of superheated steam. It was hypothesised that satisfactory application of this technique would result in improved quality of the final product, which may be recycled as a fertiliser with relatively high nutritional value or as an energy source with an enhanced heating value compared to lignite, which is considered to be low ranked coal ${ }^{27,28}$.

\section{MATERIAL AND METHODS}

Experiments were conducted using partially dried sludge and dewatered lignite-sludge mixtures. Two types of mixture ratios were investigated, $1: 1$ and $2: 1$, based on the material weights (w/w). Partially dried sludge produced by a wastewater treatment plant located in Werribee (Western Treatment Plant, Melbourne, Australia) was collected from drying ponds. The sludge was transported to the laboratory at Monash University (Melbourne) in $50 \mathrm{~L}$ buckets by car. The sludge was very thick and had a moisture content in the range of 70 to $80 \%$ (on a wet basis). Low rank coal (LRC), also referred to as lignite or brown coal, was collected from the Victorian coal mining industry (Yallourn, Australia), and had a moisture content in the range of 60 to $70 \%$ (on a wet basis).

The sludge was collected in plastic buckets containing about $15 \mathrm{~kg}$, and placed in a fridge at $4^{\circ} \mathrm{C}$ for no more than three days until carrying out the experiment in order to preserve its original characteristics. Subsequently, the sludge was filtered using an industrial filter press for one hour. Prior to conducting the experiment, the sludge from five buckets was thoroughly mixed and representative samples were taken for determination of moisture content. The sludge was taken out of the fridge until it reached room temperature before it was mixed and placed into the rotary drying drum.

\section{Description of the rotary drum dryer}

A pilot-scale rotary drum dryer with the dimensions of $0.37 \mathrm{~m}$ in diameter and $3 \mathrm{~m}$ in length was used to perform the drying of sludge and sludge-lignite mixtures. The apparatus consists of a direct contact rotary drum with concurrent flow of gas and solids as described in detail in a study by Hamawand and Yusaf (2014) ${ }^{\mathbf{1 1}}$. The rotary cylinder was made of stainless steel and both ends were sealed to prevent gas leakage from the drum $^{29}$. The entire surface area of the drum was insulated with glass wool and covered with aluminium foil. The drum cylinder rested on a pair of metal wheels on each side of the drum. The drum can be operated at rotational speeds ranging between two and $16 \mathrm{rpm}$. Four removable lifters were equally distributed around the circumference and bolted to the inside surface of the cylinder. An electrical fan was used to provide gas flow to the drum, the velocity of which could be varied between one and three meters per second. The solids were continuously fed to the drum by means of a screw driver located in the front of the drum operated by an electronic controller. A schematic diagram of the drum is shown in Figure 1.

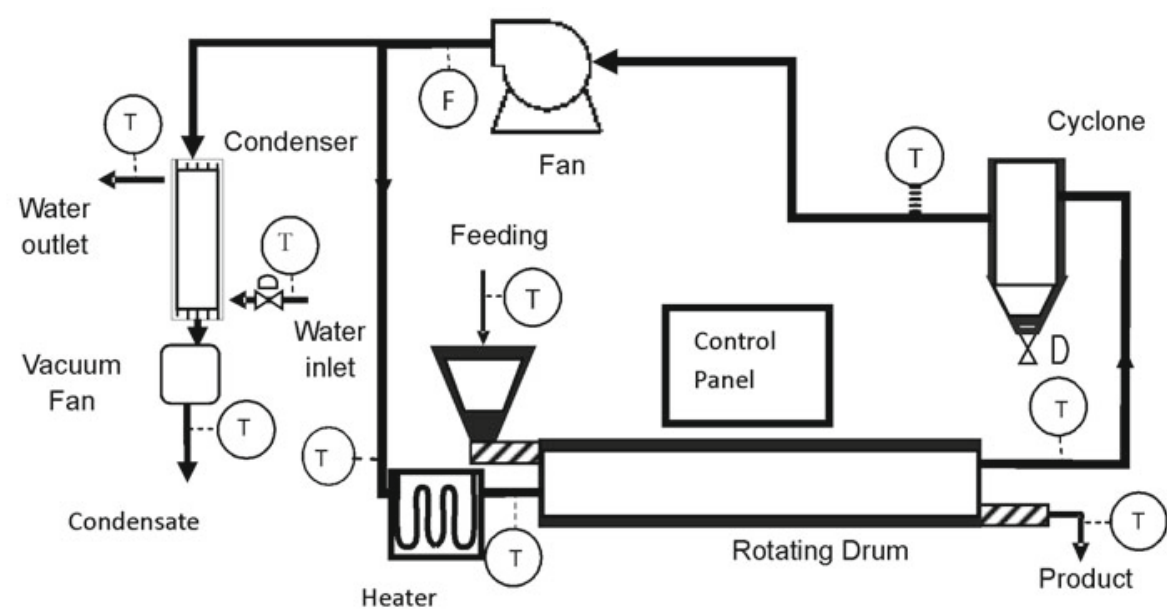

Figure 1. Schematic diagram of the industrial rotary drum dryer used to carry out the experiments 


\section{Operating conditions}

The experiment was conducted in a horizontal pilot plant drum dryer described in Figure 1. The operating conditions of the drying system were as follows: $100 \%$ steam drying medium, steam temperature around 240 $\pm 5^{\circ} \mathrm{C}$, feed flow rate programmed at $0.5 \mathrm{~kg} / \mathrm{min}$, recycled steam speed at $1.5 \mathrm{~m} / \mathrm{s}$, and drum rotation speed fixed at nine rpm. These conditions were selected based on some preliminary experiments and a modelling study carried out by the author for the same rotary drum dryer ${ }^{11}$. The operational conditions are specified in Table 1 . Due to the closed and recycling system, the water evaporated from the materials created an over-saturated drying medium. For this reason, $10 \%$ of the steam was extracted from the system using an air pump at a speed of $1.2 \mathrm{~m} \mathrm{~s}^{-1}$, the diameter of the pipe connected to the pump was five $\mathrm{cm}$. This was turned on for five minutes every half hour. The preliminary experiments showed that extraction of some of the steam from the system is important to prevent decline in the drying efficiency due to condensation when the steam becomes over-saturated. Subsequently, the drum was heated for an hour before the experiment was started, and water was sprayed into the drum for five minutes to generate steam following preheating of the drum. The feed was started when the drum reached the required operating conditions. The experimental conditions shown in Table 1 were selected as a starting point. These parameters such as steam temperature, steam flow rate, feed flow rate and drum rotation speed were modified during the course of the experiment to determine their effect on the final moisture content of the product.

Table 1. Specifications of the operating conditions

\begin{tabular}{|l|c|}
\hline Status & Specifications \\
\hline Steam percentage & $100 \%$ \\
\hline Set temperature & $240 \pm 5^{\circ} \mathrm{C}$ \\
\hline Feed flow rate & $0.5 \mathrm{~kg} \mathrm{~min}^{-1}$ \\
\hline Steam speed & $1.5 \mathrm{~m} \mathrm{~s}^{-1}$ \\
\hline Drum rotational speed & $9 \mathrm{rpm}$ \\
\hline Drum Slope & Horizontal \\
\hline
\end{tabular}

\section{RESULTS AND DISCUSSION}

The results were divided into three categories: drying of partially dried sludge from the drying ponds, drying of sludge-lignite mixtures at ratios of $2: 1$ and $1: 1(\mathrm{w} / \mathrm{w})$, and drying of lignite.

\section{Drying of partially dried sludge}

The mean moisture content (triplicate) of the sludge fed to the drum was around $77 \%$.

\section{Drying process}

The partially dried sludge was the first waste to be tested. After feeding the drum with this material for more than one hour, no product was discharged from the drum. Then big sized chunks of sludge $(>10 \mathrm{~cm}$ diameter) rolled through the drum with very low displacement toward the end of the drum as shown in Figure 2. A video camera was used to record the whole experiment for observational analysis.

Figure 3 shows the moisture content of the materials as a function of drying time. The mean moisture content of the discharged material was $69 \%$ (wet basis).

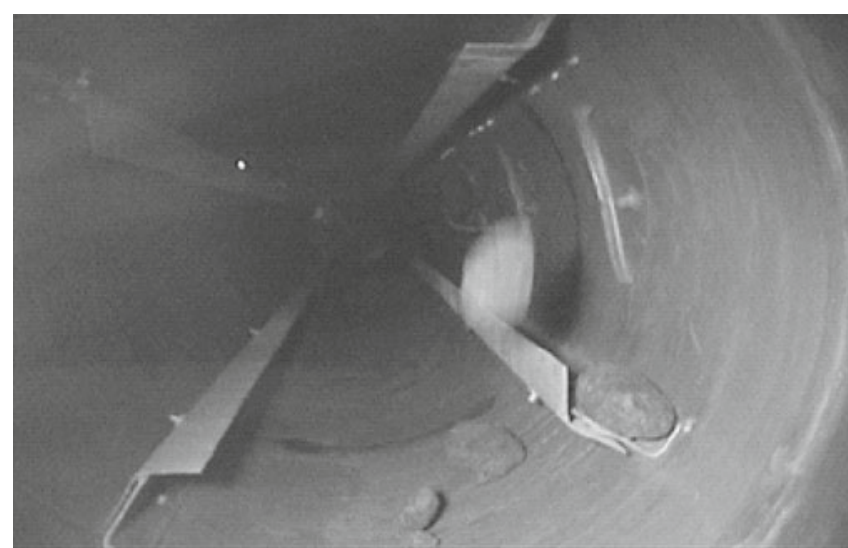

Figure 2. A picture taken from the front of the drum after 90 minutes

The moisture content of the material remained almost unchanged after 150 minutes from the start of the drying process. The conditions of the experiment such as drum rotational speed, drying temperature, steam flow rate and feed flow rate were then changed. The changes were: increasing the drying medium temperature to $240^{\circ} \mathrm{C}$, decreasing the feed flow rate to $0.5 \mathrm{~kg} / \mathrm{min}$ and increasing the steam flow rate to $1.5 \mathrm{~m} / \mathrm{s}$. This was done to increase the heat transfer coefficient in order to reduce the moisture content of the material. The rotational velocity of the drum was also reduced to increase the residence time and allow for more efficient drying. Although the parameters that control the drying process were manipulated to achieve products with low moisture content, sticking remained as the main issue preventing efficient drying. Most of the sludge fed into the drum stuck to the inner surface close to the entrance, while large lumps of sludge were produced during the entire drying period. These results confirm that partially dried sludge has significant cohesive and adhesive forces. When the cold sludge (room temperature, $20 \pm 2^{\circ} \mathrm{C}$ ) was introduced into the drum through the screw feeder, a layer of condensed water formed around it. The thickness of this layer is related to the size of the sludge cluster ${ }^{30}$. It is deducted that the initial condensation was the main factor responsible for initiating the sticking of sludge particles to the drum surface and the subsequent formation of larger aggregates of sludge within the drum ${ }^{\mathbf{1}}$. The accumulation of sludge in the drum was attributed to two main factors, namely, the initial condensation and the large particle size of the sludge generated by the feeding screw mechanism. The characteristic of interaction between a particle and a metal surface is strongly modified by the water meniscus. This meniscus results in an additional capillary force increasing the adhesion of the particles to the surface. The liquid bridge and the water meniscus, due to initial condensation, may be dominant at the beginning of drying.

\section{Stickiness}

The main factors affecting the stickiness of a material are the temperatures corresponding to glass transition and sticky point ${ }^{1}$. Hamawand, $(2011)^{1}$ reported that glass transition temperature is virtually the same as the sticky point temperature measured using thermo-mechanical tests. Principal components found in food contain low molecular weight sugars and some organic acids, 


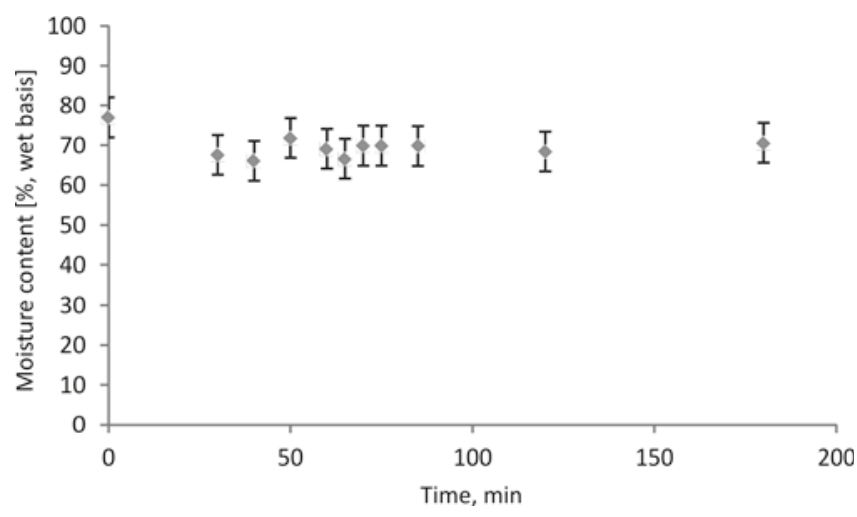

Figure 3. Mean moisture content of the sludge materials as a function of drying time $(\mathrm{n}=3)$. The error bars denote a $\pm 5 \%$ deviation from the mean value

which normally exhibit relatively low glass transition temperatures $(\mathrm{Tg})$ but can be very hygroscopic in their amorphous state. The glass transition temperature is the point at which amorphous materials show a transition from a hard and relatively brittle state to a molten or rubber-like state. Water acts as plasticizer and decreases the glass transition temperature. Differential scanning calorimetry (DSC) was used to measure the glass transition temperature of the partially dried sludge. The sample was tested and the results are shown in Figures 4 and 5. Figure 5 shows the enlarged part where the glass transition temperature appears. The figures show clearly the melting peak followed by decomposition. This suggests that the liquid associated with the sludge is contaminated with small sized particles which causes it to behave like condensed slurry ${ }^{1}$. The figures show that the glass transition temperature of the sludge sample was approximately $-23^{\circ} \mathrm{C}$. This result illustrates the stickiness of the material at temperatures higher than $-23^{\circ} \mathrm{C}$. The effect of particle size on sticking has been well studied in the literature. As the particle size reduces, the cohesion and the adhesion forces increase. During drying, droplets of amorphous solution become concentrated at their evaporation surface and can change state from a viscous fluid to a rubbery and to a glassy state as the moisture content decreases. This solid or glass bridge may be weak or strong because its strength depends only on the total area of the junction between the particle and the surface.

\section{Drying of sludge-lignite mixtures}

The sludge was mixed with lignite at different ratios. The mixture was then stored in the fridge in plastic buckets of $15 \mathrm{~kg}$ capacity each until used.

\section{Sludge-Lignite mixture 2:1}

The results corresponding to the 2:1 sludge-lignite mixture showed that the mean initial moisture content on a wet basis was $75 \%$. This initial moisture content corresponds to that determined prior to placing the material into the drum. Feeding the materials into the drum was initiated after one hour following preheating. In this experiment, there was no significant sticking to the drum surface, but agglomeration occurred to a large extent, which resulted in the formation of large aggregates in the drum as shown in Figure 6.

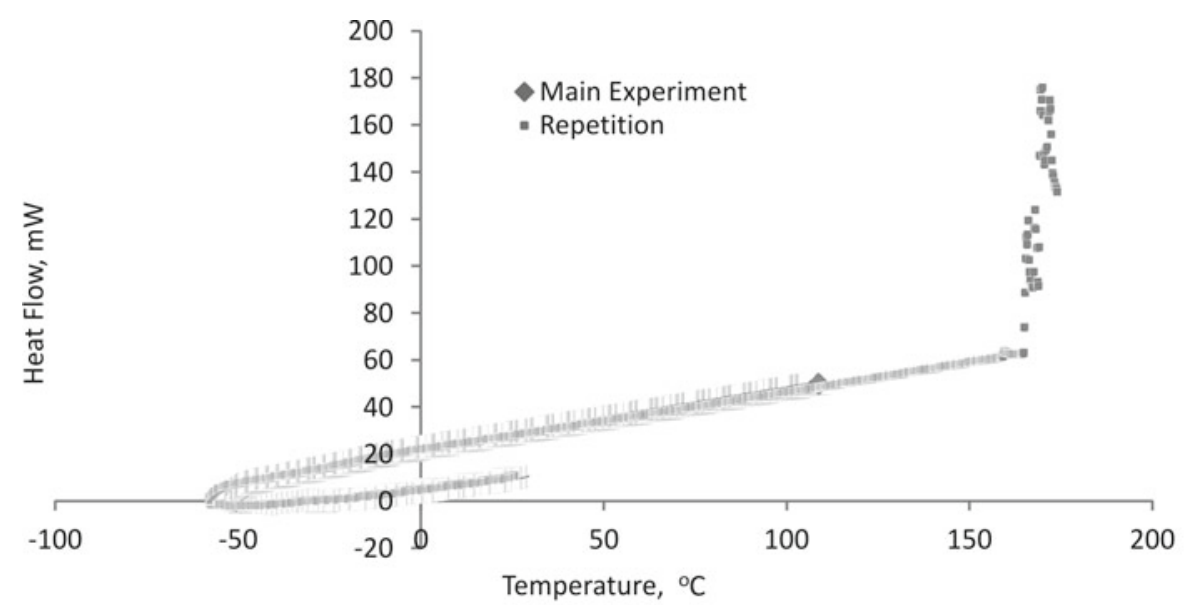

Figure 4. Differential scanning calorimerty showing the relationship between heat flow and temperature for partially dried sludge samples

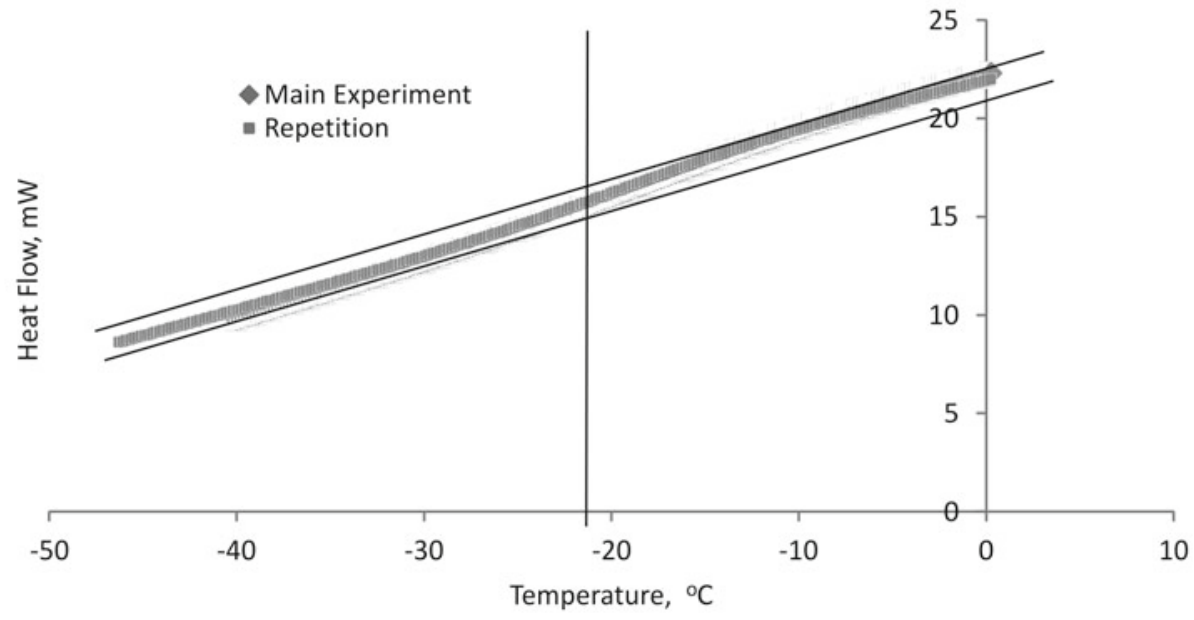

Figure 5. Magnified Differential scanning calorimerty (DSC) results for the partially dried sludge samples 


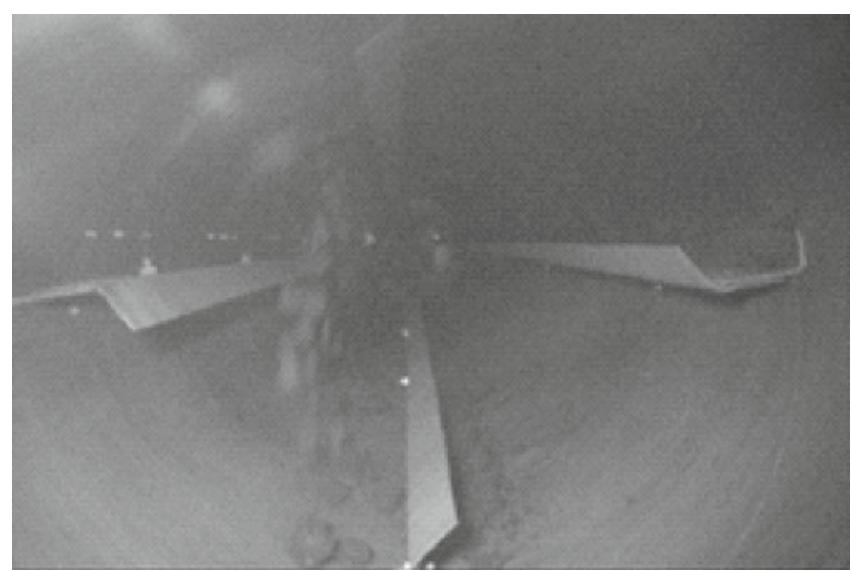

Figure 6. A picture showing the formation of relatively large aggregates inside the drum as recorded 30 minutes after the drying process was initiated

As expected, the final average moisture content was close to the initial moisture content of around $66 \%$ (wet basis), which reflects the negative impact of agglomeration during drying, as shown in Figure 7. Despite the change in moisture content between partially dried sludge (77\%) and the mixture 2:1 sludge-lignite mixture (75\%) is only $2 \%$, the addition of lignite significantly reduced sticking of the material to the surface of the drum and the agglomeration of the materials into large clusters. The materials showed a dry appearance from outside due to the high porosity of the lignite coal. This has reduced free moisture at the surface of the materials and as a result reduced the liquid bridge effect.

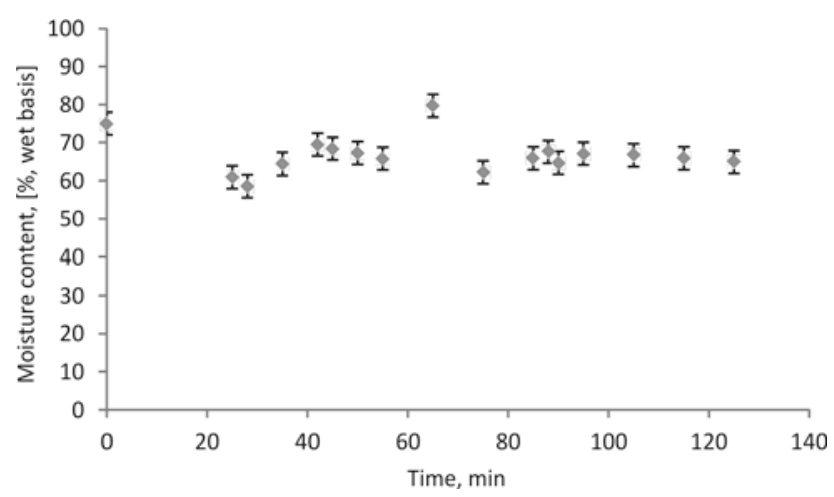

Figure 7. Mean moisture content corresponding to the material containing a mixture of 2:1 lignite-sludge $(\mathrm{n}=3)$. Deviation of the triplicate samples from the mean value $( \pm 3 \%)$

Figure 8 shows product outlet flow rates as a function of time after feeding was stopped. These data were used to estimate the residence time of the sludge-lignite mixture, which was approximately 21 minutes $^{11}$. In this experiment, the largest particle size of the material was around $200 \mathrm{~mm}$ in diameter, which affected the efficiency of drying. In addition, it appears that a residence time of 21 minutes is not sufficient to dry the materials to the required standard. Most of the drying occurs while the particles are falling into the gas-solids contact space. The importance of the residence time in the rotary drum is due to its effect on both heat and mass transfer; both of which are the main factors for successful design. The time interval of contact with the inlet gas and axial position in the drum are very important variables for the heat transfer calculations because the drying medium changes temperature axially through the drum ${ }^{12}$.

It is therefore important to optimise residence time to ensure the final product has the required low moisture content and that there is no unnecessary energy consumption. The mean inlet and outlet temperatures of the saturated superheated steam were approximately 160 and $110^{\circ} \mathrm{C}$, respectively, as shown in Figure 9. There was a $50^{\circ} \mathrm{C}$ difference between the inlet and the outlet steam temperatures, which reflects poor drying efficiency since most of this energy dissipated from the surface area of the drum.

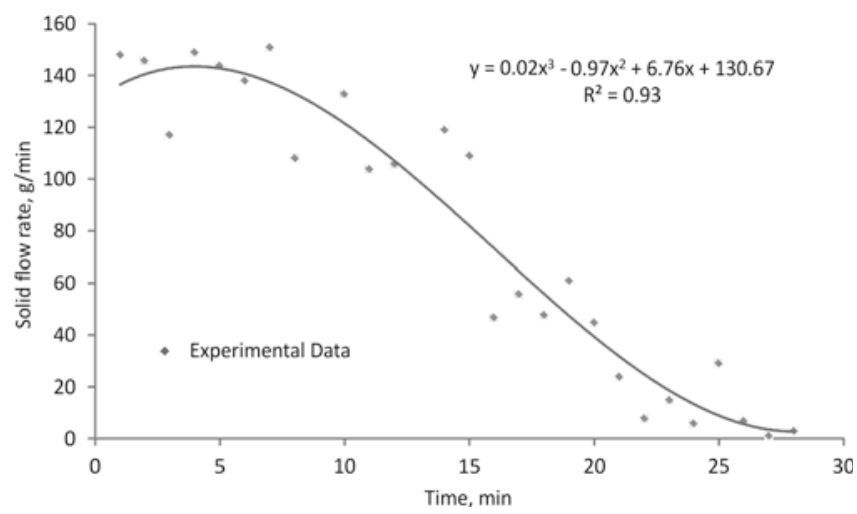

Figure 8. Relationship between product flow rate at the exit of the drum and time corresponding to the 2:1 sludgelignite mixture. hold up $2640 \mathrm{~g}$, feed flow rate is 500 $\mathrm{g} \mathrm{min}^{-1}$, and residence time is $21.2 \mathrm{~min}$

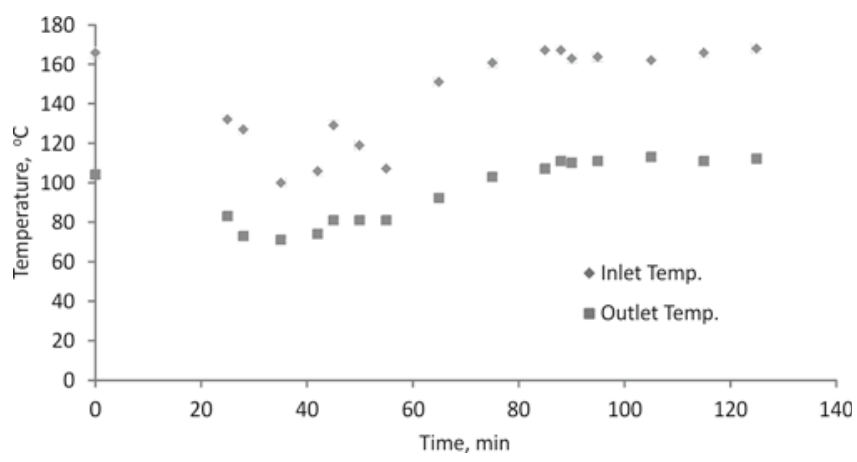

Figure 9. Relationship between steam temperature and time corresponding to inlet and outlet

\section{Sludge-Lignite mixture 1:1}

For the 1:1 sludge-lignite mixture, the mean (initial) moisture content on a wet basis was $72 \%$. Figure 10 shows the relationship between moisture content of the product and time. The average moisture content of the product was around $60 \%$. The drying efficiency of this mixture did not differ significantly from that encountered for the 2:1 mixture, which can be attributed to the relatively large particle size range of the material. The largest particle size of the product in this case was approximately $50 \mathrm{~mm}$ in diameter, which is significantly smaller than that encountered for the 2:1 sludge-lignite mixture. Figure 11 shows the results corresponding to the inlet and outlet temperatures of the drying medium. The steam inlet recorded a mean temperature of $165^{\circ} \mathrm{C}$ whereas for the steam outlet this was $75^{\circ} \mathrm{C}$. However, the high energy consumed by the dryer $\left(\Delta \mathrm{T}=90^{\circ} \mathrm{C}\right)$, the particle size effect on the drying process was obvious. The greater the size of the sample, the greater amount of steam condenses on its surface. In steam drying, there are 
no moisture losses from the sample until it reaches the saturation temperature, close to $100^{\circ} \mathrm{C}$, where moisture begins to evaporate from the surface. When the moisture content reaches a critical point, the temperature of the sample starts to rise. The steam condensation leads to an increase in the moisture content of the materials introduced into the dryer before it starts to dry.

For this reason, the particle size of the product was studied to provide a better understanding of the drying process.

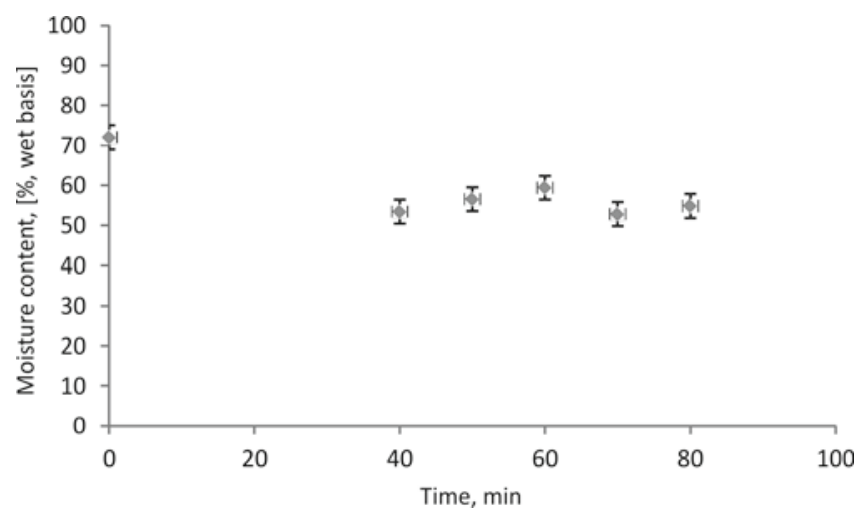

Figure 10. Relationship between mean moisture content of the 1:1 lignite-sludge mixture and drying time $(n=3)$. Deviation of the triplicate samples from the mean value $( \pm 5 \%)$

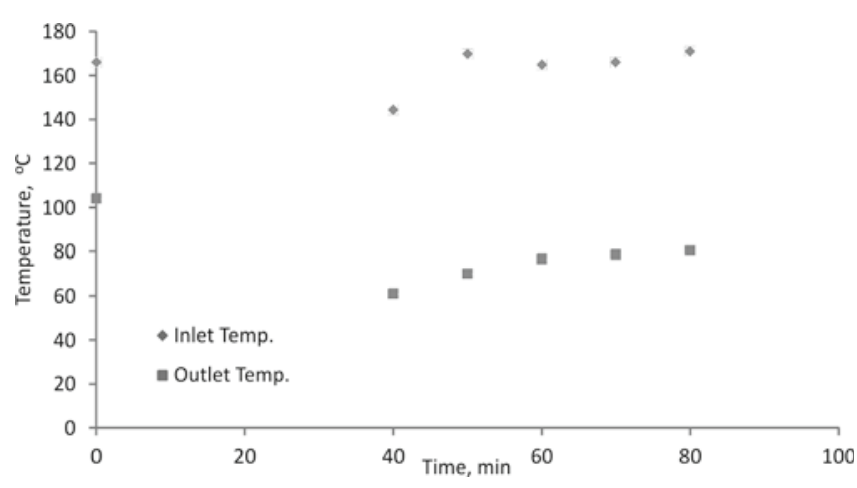

Figure 11. Relationship between inlet and outlet steam temperatures and time

Figure 12 shows the agglomerated particles as they are rolling over the inner surface of the drum during the drying process. The particle size analysis of the final product after drying is shown in Figure 14. The final moisture content of the material was related to particle size as the smallest particles in the sample (ranging from two to four millimetres in diameter) exhibited relatively lower moisture content (approximately 22\%) compared with larger particles. Particles greater than $15 \mathrm{~mm}$ in diameter showed the highest moisture content (approximately $70 \%$ ). This emphasises the negative effect of material agglomeration on the overall drying performance of the final product. As a result of increased particle size, the drying efficiency is significantly reduced. Consequently, the residence time for particles greater than $15 \mathrm{~mm}$ in diameter needs to be longer than 21 minutes to provide satisfactory results. It seems there is an interaction between size of the particles, initial condensation and agglomeration behaviour of the materials. As the initial condensation increases, the agglomeration increases which leads to bigger particles and a higher amount of steam condensation on its surface. In a study by Hamawand et al. (2014) $)^{\mathbf{2 2}}$, the amount of initially con- densed steam on the sample's surface was doubled as the thickness of the sample increased from 2 to $6 \mathrm{~mm}$. In fact, the increase in the size of the sample requires more steam to condense on its surface in order to raise its temperature to saturation $\left(100^{\circ} \mathrm{C}\right)$. As observed during the experiments, the condensed steam formed big water droplets at the base of the samples.

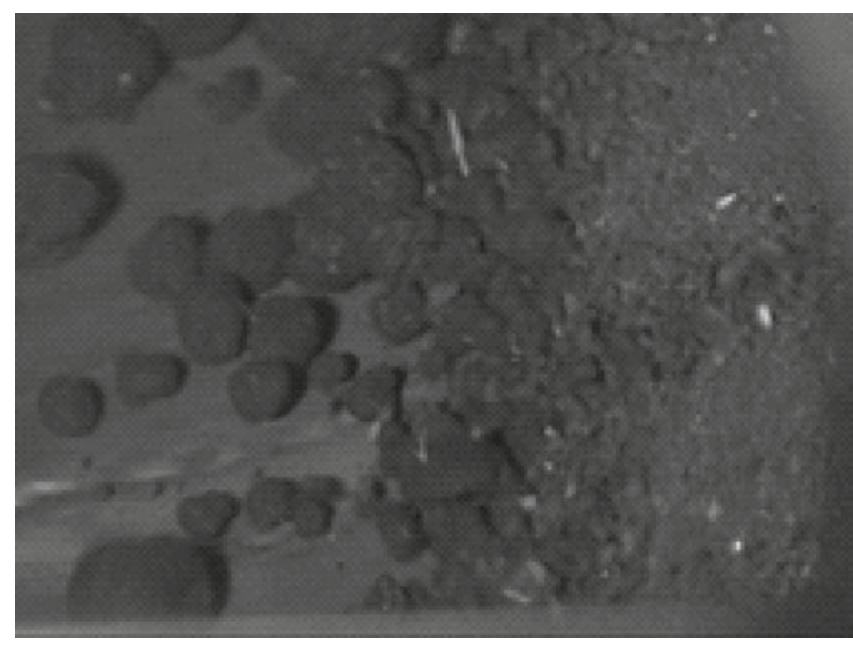

Figure 12. A picture taken from the front of the drum showing the 1:1 sludge-lignite mixture
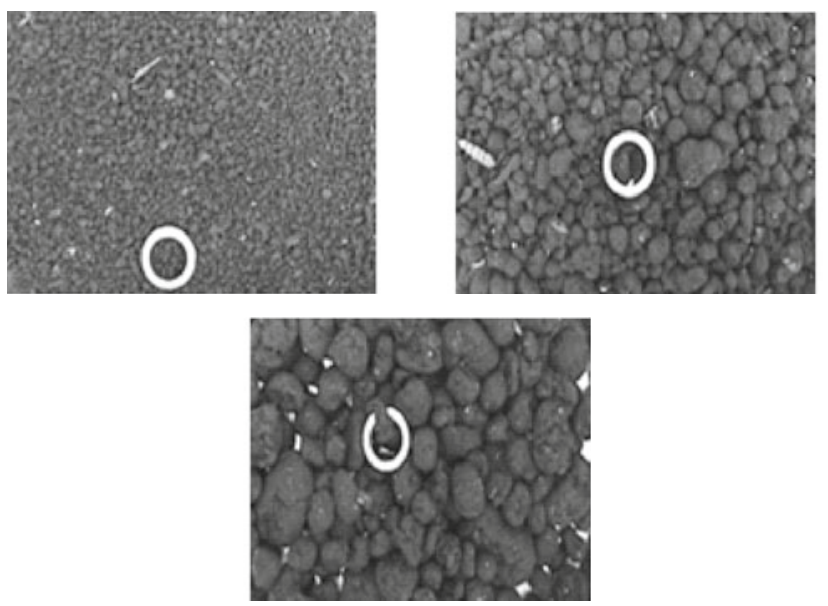

Figure 13. Pictures taken for the product with three particle size categories, reference ring diameter $10 \mathrm{~mm}$, from left to right: $(\mathrm{A}<4 \mathrm{~mm})$ M.C. $22 \%,(4 \mathrm{~mm}<\mathrm{B}<8 \mathrm{~mm})$ M.C. $56 \%$, and $(8<\mathrm{C}>15 \mathrm{~mm})$ M.C. $66 \%$

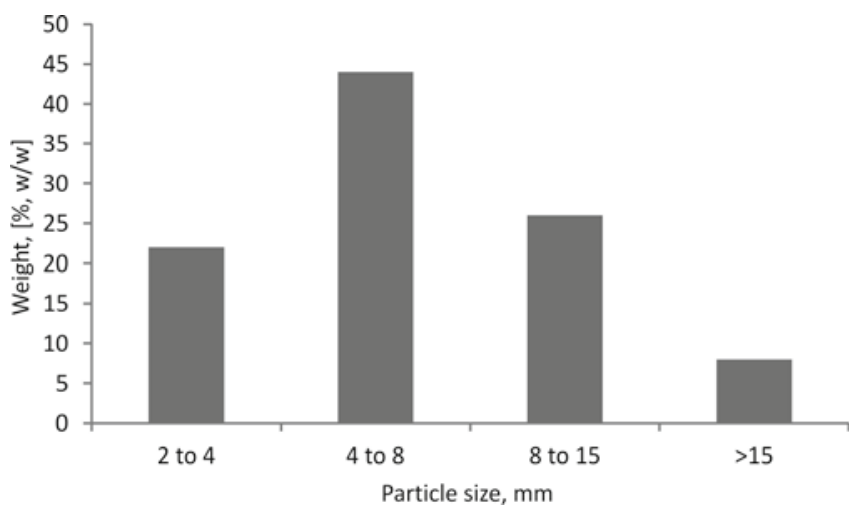

Figure 14. Particle size distribution of the dried product

\section{Lignite}

Many experiments were carried out with different initial moisture contents of coal and lignite from the 
mine. The aim of these experiments was to investigate the agglomeration behaviour of the lignite particles over a range of different moisture contents. The range of moisture contents of the lignite was prepared between $57 \%$ (original moisture content of the coal) and $68 \%$ by adding water to the material. The second column in Table 2, shows the moisture content as planned for the experiments and the last column is the actual moisture content of the material after preparation. After starting the feeding, three samples of the product were taken every 15 minutes and the average moisture content was measured as shown in Table 2, column five. It was also deducted that the average moisture content of the product increases with increasing moisture content of the feeding material. It was observed that an increase in the initial moisture content of the material resulted in an equal increase in the moisture content recorded at the end of the drying process; e.g., a $10 \%$ increase in the initial moisture content led to about $10 \%$ increase in the moisture content in the final product. Figure 15 shows the agglomerated particles of lignite during the drying process at different feed moisture contents. The particle size range of the product increased when the initial moisture content of the feed was increased as shown in Figure 16, which also increased the agglomeration of the material.

Moisture content was found to influence the moisture agglomerate size. The processes of agglomerate destruction and growth are balanced based on its critical moisture content. Larger agglomerates had lower critical initial moisture content than smaller agglomerates. Agglomerates will grow in size when their moisture content higher than these critical values. While agglomerates with moisture content lower than these critical values will decrease in size when the erosion mechanism of agglomerate destruction is dominant $t^{31}$.

Table 2. Moisture content of the feed and the product of pure lignite from the mine

\begin{tabular}{|c|c|c|c|c|c|}
\hline $\begin{array}{l}\text { Time } \\
{[\mathrm{min}]}\end{array}$ & $\begin{array}{c}\text { Initial moisture } \\
\text { content [\%], planned }\end{array}$ & $\begin{array}{l}\text { Initial weight of } \\
\text { the product [g] }\end{array}$ & $\begin{array}{c}\text { Final weight of the } \\
\text { product [g] }\end{array}$ & $\begin{array}{l}\text { Moisture content of } \\
\text { final product, [\%] }\end{array}$ & $\begin{array}{l}\text { Initial moisture content [\%], } \\
\text { checked }\end{array}$ \\
\hline 0 & 57 & 3.9 & 2.98 & 23.58 & 57.00 \\
\hline 15 & 57 & 4.1 & 2.91 & 29.02 & \\
\hline 45 & 57 & 5.9 & 5.32 & 9.83 & \\
\hline 0 & 60 & 3.8 & 3.55 & 6.57 & 58.58 \\
\hline 15 & 60 & 9.4 & 7.4 & 21.27 & \\
\hline 45 & 60 & 4.5 & 3.84 & 14.66 & \\
\hline 15 & 62 & 9 & 8.16 & 9.33 & \\
\hline 45 & 62 & 7.7 & 6.15 & 20.12 & \\
\hline 0 & 63 & 13.1 & 12.38 & 5.49 & 61.43 \\
\hline 15 & 63 & 26.3 & 24.91 & 5.28 & \\
\hline 45 & 63 & 13.2 & 12.15 & 7.95 & \\
\hline 0 & 65 & 9.3 & 8.93 & 3.97 & 63.26 \\
\hline 15 & 65 & 10.1 & 8.57 & 15.14 & \\
\hline 45 & 65 & 6.2 & 5.87 & 5.32 & \\
\hline 15 & 66 & 8.4 & 5.22 & 37.85 & \\
\hline 45 & 66 & 11.1 & 7.01 & 36.84 & \\
\hline 0 & 67 & 6.3 & 5.2 & 17.46 & 65.68 \\
\hline 15 & 67 & 46.4 & 27.52 & 40.68 & \\
\hline 45 & 67 & 11.5 & 7.27 & 36.78 & \\
\hline 0 & 68 & & & & 66.92 \\
\hline 15 & 68 & 32.6 & 22.45 & 31.13 & \\
\hline 45 & 68 & 36.5 & 25.66 & 29.69 & \\
\hline
\end{tabular}
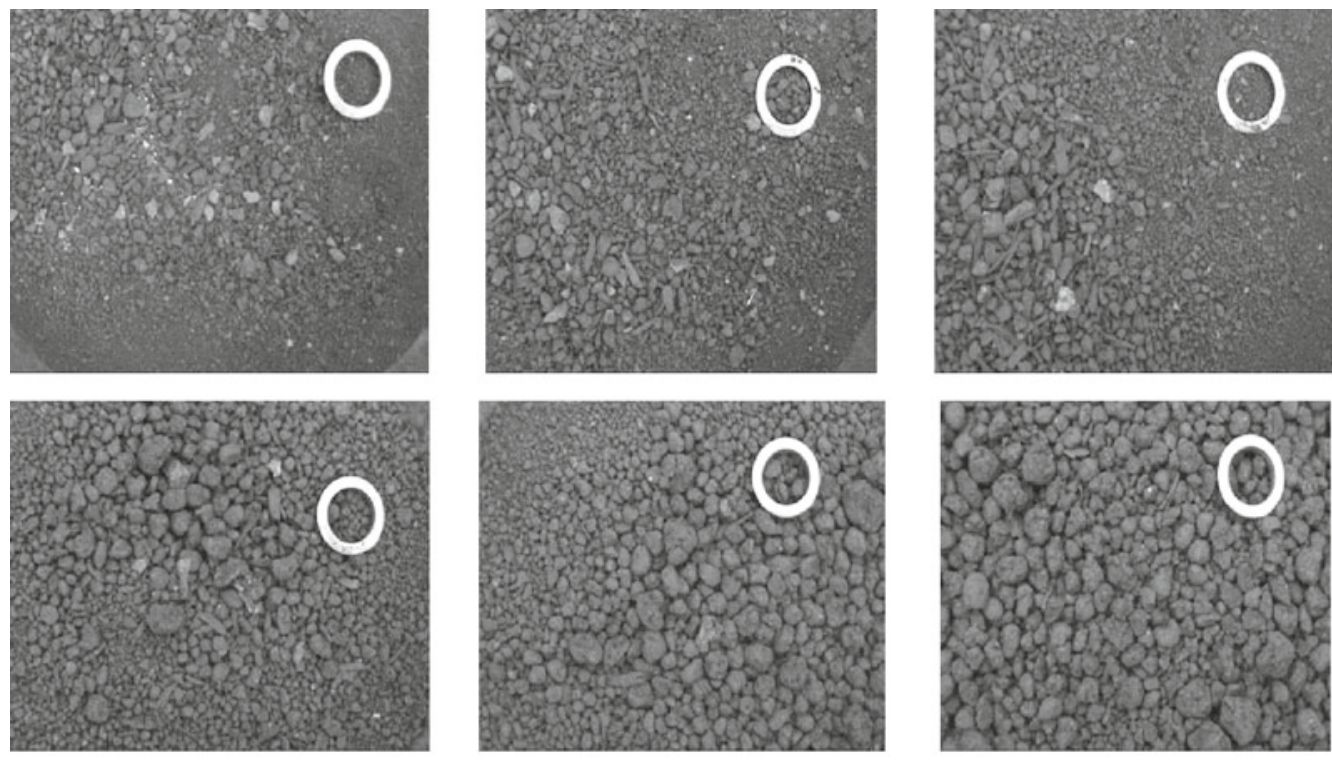

Figure 15. Pictures taken for the product samples for different moisture content of the feed $57,60,62,63,65,66,67$, and $68 \%$ from left to right and top to bottom, respectively, pure lignite from the mine, ring diameter is $10 \mathrm{~mm}$ 


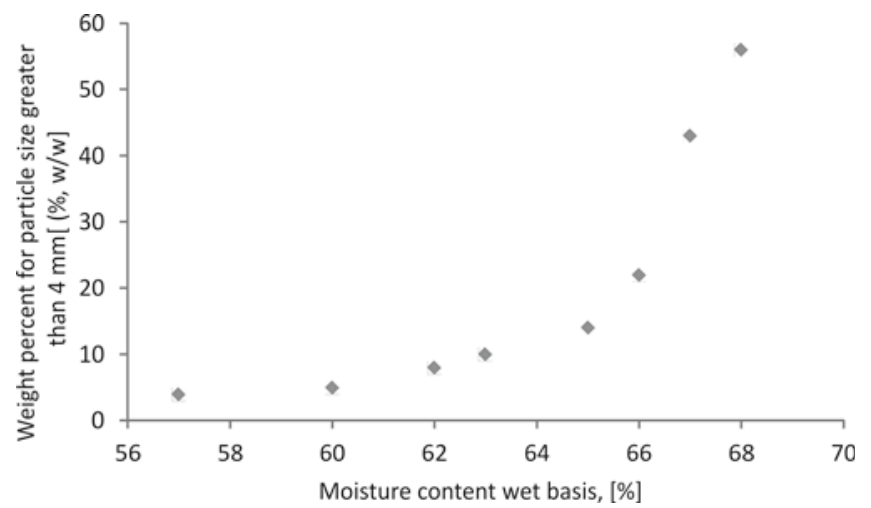

Figure 16. Relationship between particle size of the product for particles greater than $4 \mathrm{~mm}$ in diameter and moisture content of the feed

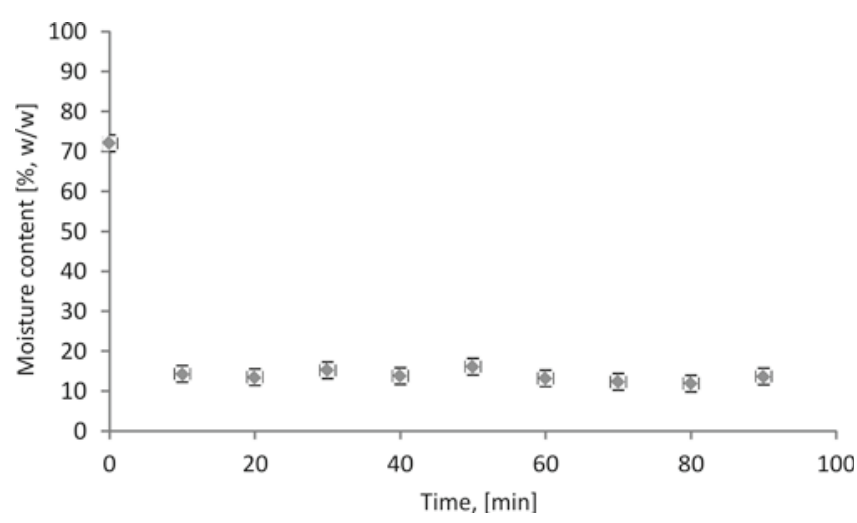

Figure 17. Moisture content of the product of the chopped 1:1 lignite-sludge mixture as a function of time

This experiment confirmed that a larger proportion of particles greater than four millimetres in diameter reduced the overall efficiency of the drying process. Since the initial moisture content of the filtered sludge and lignite mixture cannot be controlled, the efficiency of the drying process can only be enhanced by ensuring that the particle size of the material is within a specified range (equal or less than four millimetres).

\section{Optimum results}

The final experiment was conducted to overcome the problem of agglomeration during the particles' rolling in the drum. The experiment was carried out with the 1:1 sludge-lignite mixture. The initial average moisture content of the feed was $72 \%$. In this experiment the feeding materials were pre-treated, first chopped to a small particle size and then sieved with four millimetres mesh sieve. The chopping process was carried out manually using a shovel with a flat blade fixed to one end of the handle. The material was first spread over a large plastic rug and then chopped manually. As shown in Figure 17, the mean moisture content on a wet basis of the product was $15 \%$, which was a significant improvement in the drying efficiency compared with the previous mixtures. The moisture content was reduced by about $60 \%$ compared with the $1: 1$ sludge-lignite mixture without pre-preparation. Therefore, the chopping process created individual clusters which are difficult to agglomerate even after going through the screw feeder. This may be attributable to the relatively low force of the liquid bridge between the clusters compared to the weight of each cluster. In addition, smaller sized particles condense a smaller amount of steam when initially introduced to the dryer. This is an important factor in prohibiting any increase in the initial moisture content of the materials. As shown previously (section 3.2.3), any increase in the initial moisture content of the materials leads to an increase in the agglomeration behaviour. Moreover, an increase in the amount of lignite in the mixture reduced the availability of free moisture on the surface of the particles. This is due to the high porosity of the lignite coal.

Around $85 \%$ of the product mass consisted of particles with a diameter of four millimetres or less as shown in Figures 18 and 19. Only a small portion of the feeding materials was agglomerated to larger particle size clusters.

The temperature of the inlet and the outlet of the drum were monitored as shown in Figure 20. The temperature was more stable in this situation for both the inlet and the outlet. The temperature difference was increased to
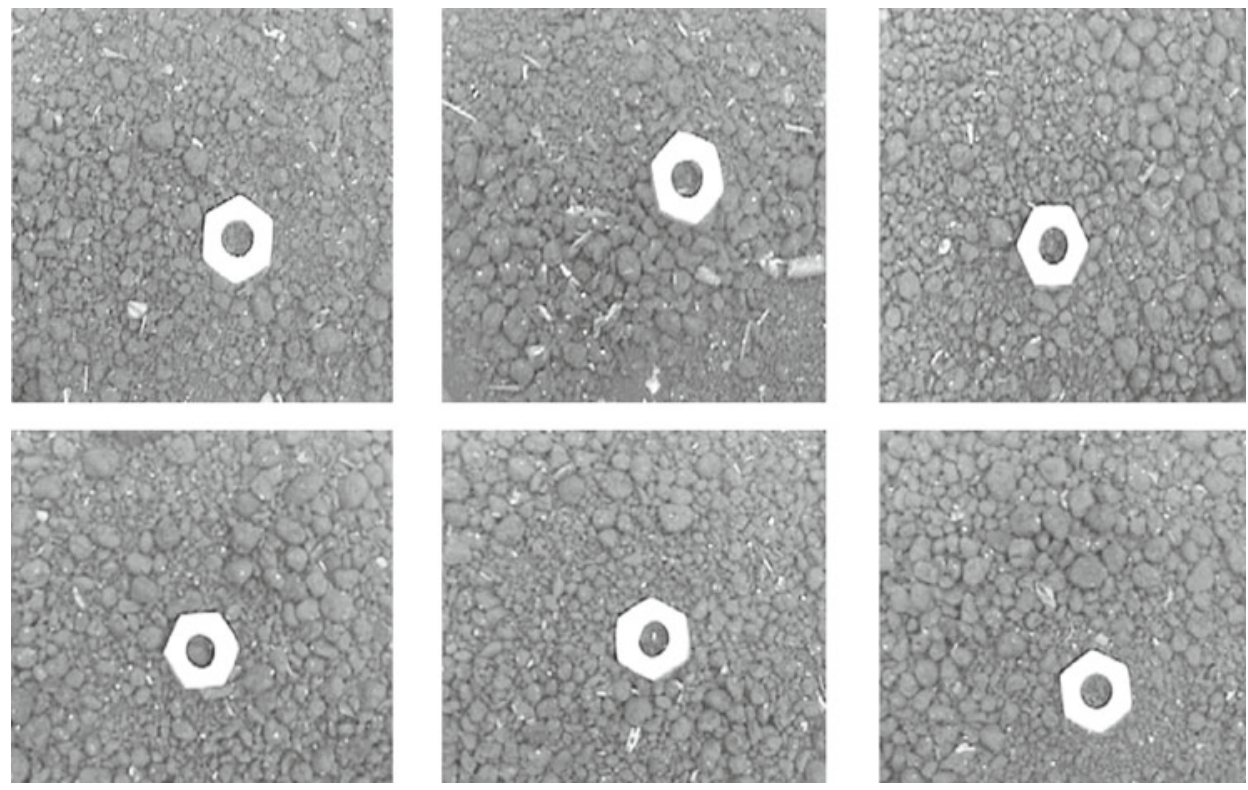

Figure 18. Pictures taken for the samples of the product at different periods, chopped 1:1 sludge-lignite mixture, hexagonal shape diameter is $10 \mathrm{~mm}$ 


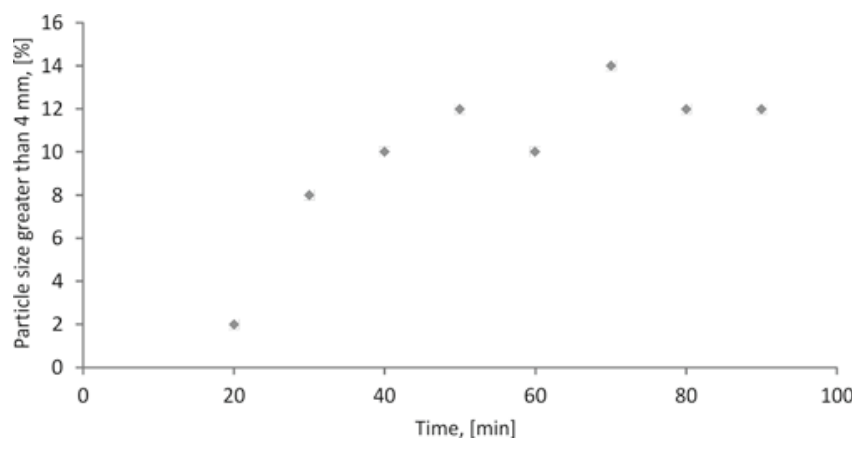

Figure 19. Product's particle size greater than $4 \mathrm{~mm}$ vs time

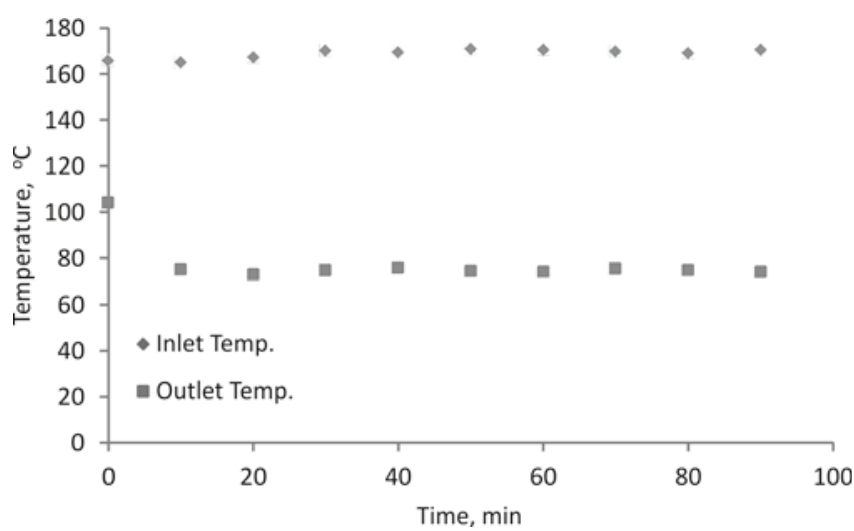

Figure 20. Steam temperatures corresponding to inlet and outlet, respectively

around $100^{\circ} \mathrm{C}$. This clearly illustrates the enhancement in the drying process.

\section{CONCLUSIONS}

This study addressed engineering aspects of two issues associated with drying under superheated steam in a rotary drum dryer. The sticking nature of the materials exhibited a significant effect on the moisture content of the dried product. Adhesion led to sticking of the sewage sludge to the drum surface and cohesion induced the formation of relatively large particles during the drying process. These two phenomena were the most notable problems of the drying process. In order to produce products with specific moisture content, these two phenomena were controlled. In this research the adhesion of the sludge to the drum surface was controlled by adding brown coal (lignite). When partially dried sludge was fed to the drum, most of the sludge stuck to the drum surface at the entrance. In contrast, the mixture of sludge and lignite showed no sticking to the drum surface. This approach solved the adhesion problem of sludge and reduced the agglomeration issue to a large extent. Particles sized larger than four millimetres showed a significant impact on the moisture content of the product. Chopping the mixture and then sieving it with a four millimetre mesh sieve was able to reduce the moisture content of the product to approximately $15 \%$, this was a significant improvement in the drying efficiency compared with the previous mixtures.

\section{ACKNOWLEDGMENT}

Thanks to Keith Engineering (Pinches) Pty Ltd Australia for providing the rotary drum dryer for carrying out this experiment. Also, thanks go to Dilip Desai for his great assistance and valuable advices. The experiments were carried out at Monash University, Chemical Engineering Department, Clayton, Melbourne.

\section{LITERATURE CITED}

1. Hamawand, I. (2011). Effect of Colloidal Particles associated with the Liquid Bridge in Sticking during Drying in Superheated Steam. Inter. J. Engineer. 24(2), 119-126.

2. Bhandari, B. \& Howes, T. (2005). Relating the stickiness property of food undergoing drying and dried products to their surface energy. Drying Technol. 23, 781-797. DOI: 10.1081/DRT-200054194.

3. Mazzone, D.N., Tardos, G.I. \& Pfeffer, R. (1987). The behaviour of liquid bridges between two relatively moving particles. Powder Technol. 51, 71-83. DOI: 10.1016/00325910(87)80041-4.

4. Adhikari, B., Howes, T., Bhandari, B.R. \& Truong V. (2001). Stickiness in foods: A review of mechanisms and test methods. Inter. J. Food Proper. 4 (1), 1-33. DOI: 10.1081/ JFP-100002186.

5. Mu, Fusheng \& Su Xubin. (2007). Analysis of liquid bridge between spherical particles. China Particuology 5, 420-424. DOI: 10.1016/j.cpart.2007.04.006.

6. Font, R., Gomez-Rico, M.F. \& Fullana, A. (2011). Skin effect in the heat and mass transfer model for sewage sludge drying. Sep. Puri. Technol. 77, 146-161. DOI: 10.1016/j. seppur.2010.12.001.

7. Bennamoun, L., Arlabosse, P. \& Léonard, A. (2013). Review on fundamental aspect of application of drying process to waste water sludge. Renewable and Sustainable Energy Rev. 28, 29-43. DOI: 10.1016/j.rser.2013.07.043.

8. Pajak, T. (2013). Thermal Treatment as Sustainable Sewage Sludge Management. Environ. Protect. Engineer. 39(2), 41-53. DOI: 10.5277/EPE130205.

9. Mathioudakis, V.L., Kapagiannidis, A.G., Athanasoulia, E., Paltzoglou, A.D., Melidis, P. \& Aivasidis, A. (2013). Sewage Sludge Solar Drying: Experiences from the First Pilot-Scale Application in Greece. Drying Technology: An Inter. J. 31(5), 519-526. DOI: 10.1080/07373937.2012.744998.

10. Li, Y., Wang, H., Zhang, J., Wang, J. \& Lan, O. (2013). CoProcessing Sewage Sludge in Cement Kiln in China. J. Water Res. Protect. 5, 906-910. DOI: 10.4236/jwarp.2013.59093.

11. Hamawand, I. \& Yusaf, T. (2014). Modelling the Particle Motion in a Cascading Rotary Drum Dryer. Canadian J. Chem. Engineer. 92(4), 648-662. DOI: 10.1002/cjce.21845.

12. Wardjiman, C., Lee, A., Shehan, M.E. \& Rhodes, M. (2008). Behaviour of a curtain of particles falling through a horizontally-flowing gas stream. Powder Technol. 188(2), 110-118. DOI: 10.1016/j.powtec.2008.04.002.

13. Pronyk, C., Cenkowski, S. \& Muir, W.E. Drying foodstuff with superheated steam. Drying Technol. 22(5), 899-916. DOI: $10.1081 /$ DRT-120038571.

14. Van Deventer, H.C. \& Heijmans, R.M.H. (2001). Drying with superheated steam. Drying Technol. 19(8), 2033-2045. DOI: 10.1081/DRT-100107287.

15. Soponronnarit, S., Nathakaranakule, A., Jirajindalert, A. \& Taechapairoj, C. (2006). Parboiling brown rice using superheated steam fluidization technique. J. Food Engineer. 75, 423-432. DOI: 10.1016/j.jfoodeng.2005.04.058.

16. Soponronnarit, S., Prachayawarakorn, S., Rordprat, W., Nathakaranakule, A. \& Tia, W. (2006). A superheated steam fluidized bed dryer for Parboiled Rice: testing of pilot-scale and mathematical Model Development. Drying Technol. 24(11), 1457-1467. DOI: 10.1080/07373930600952800.

17. Beeby, C. (1984). Drying in Superheated steam-fluidized bed. Unpublished doctoral dissertation, University of Monash, Melbourne, Australia. 
18. Trommelen, A.M. \& Crosby, E.J. (1969). Evaporation and drying of drops in superheated vapours. AIChE Journal. 16 (5), 857-867. DOI: 10.1002/aic.690160527.

19. Tang, Z. \& Cenkowski, S. (2000). Dehydration dynamics of potatoes in superheated steam and hot air. Can. Agric. Engineer. 42(1).

20. Elustondo, D., Elustondo, M.P. \& Urbicain, M.J. (2001). Mathematical modelling of moisture evaporation from foodstuffs exposed to subatmospheric pressure superheated steam. J. Food Engineer. 49(1), 15-24. DOI: 10.1016/S02608774(00)00180-1.

21. Pakowiski, Z., Krupinka, B. \& Adamski, R. (2007). Prediction of sorption equilibrium both in air and superheated steam drying of energetic variety of willow salix viminalis in wide temperature range. Fuel 86(12-13), 1749-1757. DOI: 10.1016/j.fuel.2007.01.016.

22. Hamawand, I. Yusaf, T. \& Bennett, J. (2014). Study and Modelling Drying of Banana Slices under Superheated Steam. Asia Pacific J. Chem. Engineer. 9(4), 591-603. DOI: 10.1002/apj.1788.

23. da Silva, W.P., Hamawand, I. \& E. Silva C.M.D.P.S. (2014). A liquid diffusion model to describe drying of whole bananas using boundary-fitted coordinates. J. Food Engineer. 137, 32-38. DOI: 10.1016/j.jfoodeng.2014.03.029.

24. Wimmerstedt, R. \& Hager, J. (1996). Steam drying - modelling and applications. Drying Technol. 14(5), 1099-1119. DOI: 10.1080/07373939608917141.

25. Hong, S., Ryu, C., Ko, H.S., Ohm, T.I. \& Chae, J.S. (2013). Process consideration of fry-drying combined with steam compression for efficient fuel production from sewage sludge. Appl. Energy 103, 468-476. DOI: 10.1016/j.apenergy.2012.10.002.

26. Iyota, H., Nishimura, N., Yoshida, M. \& Nomura, T. (2001). Simulation of superheated steam drying considering initial steam condensation. Drying Technol. 19(7), 1425-1440. DOI: 10.1081/DRT-100105298.

27. Hakli, O., Dumanli, A.G., Nalbant, A., Okyay, F. \& Yürüm, Y. (2010). The Conversion of Low-rank Kilyos Coal to Nitrogeneous. Energy Sources, Part A: Recovery, Utilization, and Environm. Effects 33(2), 164-170. DOI: 10.1080/15567030902937242.

28. Bergins, C. \& Strauss, K. (2007). Advanced processes for low rank coal drying and dewatering in high efficient power plants. Inter. J. Global Energy Issues 28(2/3), 241-263. DOI: 10.1504/IJGEI.2007.015878.

29. Pinches Industry Pty Ltd. (2014). Retrieved October 10, 2014, from http://www.pinches.com.au/

30. Hamawand, I. (2013). Drying Steps under Superheated Steam: A Review and Modelling. J. Energy Environ. Res. 3(2), 107-125. DOI: 10.5539/eer.v3n2p107.

31. Weber, S., Briensy, C., Berrutiz, B., Chan, E.W. \& Gray, M.R. (2007, May). Agglomerate Behaviour in Fluidized Beds. Refereed Proceedings The 12th International Conference on Fluidization - New Horizons in Fluidization Engineering. Retrieved April 20, 2015, from http:// dc.engconfintl.org/fluidization_xii/103/ 